\title{
El Forfaiting: Una Opción al Financiamiento del COMERCIO INTERNACIONAL
}

\author{
Recepción: Febrero de 2005 / Aceptación: Junio 2005
}

(1) Javier Del Carpio Gallegos
(2) Hércules Molina Arenaza

\section{RESUMEN}

Forfaiting es el descuento de cuentas por cobrar relacionadas a transacciones de Comercio Internacional, sin recurso para el exportador. El Forfaiting consiste en la compra de cartas de crédito de exportación y/o cobranzas avaladas. En una transacción forfaiting, el exportador acuerda entregar los derechos que se demanda para el pago de las mercancías o de los servicios entregados a un importador bajo contrato de venta, a cambio de un pago en efectivo de un banco forfaiting.

Palabras Clave: Forfaiter. Comercio internacional. Efectos a cobrar. Financiamiento. Pre-embarque.

The Forfatting: An Option to Financing the Trade International ABSTRACT

Forfaiting is the discount of accounts to receive related to transactions of Trade International, without resource for the exporter. The Forfaiting consist in letters purchase of credit of export and/or collections guaranteed. In one transaction forfaiting, the exporter decides to give the rights that demand for the payment of merchandise or services given to an importer under contract of sale, in exchange for a payment in cash of a bank forfaiting.

Key words: Forfaiter. Trade international. Effects to receive. Financing. Pre-boarding.

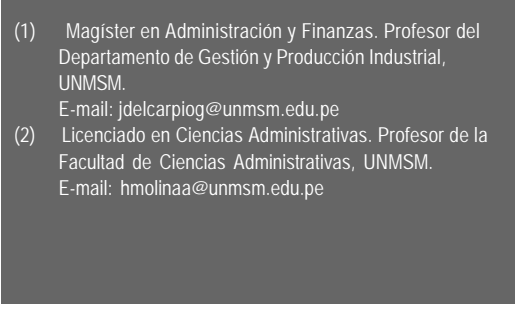

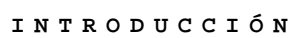

En sus inicios el mercado del forfaiting fue desarrollado por los suizos, después de la Segunda Guerra Mundial para financiar la venta de bienes de capital alemanes a Europa del Este. Pero actualmente los centros mundiales de forfaiting son Londres, Zurich y Viena, mercados donde se pactan casi la totalidad de las operaciones de forfaiting del mundo, en donde muchos bancos grandes, incluyendo las instituciones americanas, proporcionan servicios especializados de forfeiting en sus filiales. El Forfaiting se utiliza cuando los créditos a la exportación del gobierno o las garantías de crédito no están disponibles o cuando un vendedor no amplía créditos a largo plazo en los mercados, tales como Europa del Este, Latinoamérica, entre otros.

En tanto que éste procedimiento es relativamente nuevo, ciertamente esta adquiriendo importancia en el comercio internacional, y es conocido como Die forfaitierung en Alemania, la Forfetizacion en España, le Forfetizzazione en Italia, le Forfeitage en Francia.

Actualmente la mayoría de los interesados ven un mercado potencial casi ilimitado para el forfaiting, una aplicación mucho más amplia: como acciones individuales y como negociación de transacciones comerciales interrelacionadas que se pueden estructurar totalmente, tomando el riesgo de funcionamiento a través de la provisión del financiamiento del preembarque, seguido y combinado con la recepción del reembolso del postembarque del comprador.

Lo recomendable, para recibir el máximo beneficio de esta técnica de financiamiento, es acudir a un especialista en Forfaiting, antes de establecer las negociaciones con un comprador, de tal manera que la parte de los costos correspondientes al Forfaiting, puedan ser incorporados al precio de venta o en el contrato de venta. Se debe tener en cuenta que más del $5 \%$ del comercio mundial es financiado mediante esta técnica.

\section{¿QUÉ ES FORFAITING?}

El forfaiting o "recurso sin financiamiento" es un método de finanzas comerciales que puede ser de corto o mediano plazo, mediante la cual el banco (forfaiter) le compra al exportador, sin recurso, una letra, pagaré o carta de crédito diferida que representa un crédito de proveedor. En el momento de la compra del documento al exportador, el banco le adelanta los fondos aplicándole una tasa de descuento previamente pactada. El banco, al vencimiento del documento, le cobra al importador (o al banco emisor si se trata de una carta de crédito diferida). 
Forfaiting es una técnica altamente flexible que permite al exportador otorgar atractivas condiciones de crédito a su comprador en el extranjero, sin necesidad de utilizar recursos propios ni asumir riesgos de demora en pagos posteriores. Además, el exportador está totalmente protegido contra las fluctuaciones en las tasas de interés o de cambio durante el plazo del crédito.

Una extensa gama de productos y servicios son financiados por las instituciones financieras mediante el uso creativo del forfaiting, incluyendo mercancías, servicios, proyectos financieros, plantas hidroenergética e inclusive transferencias de honorarios para atletas profesionales. Los valores contractuales que pueden ser financiados mediante el forfaiting oscilan entre USD 30,000 y USD 100 millones. La simplicidad y flexibilidad del forfaiting son las razones primordiales de su éxito y popularidad alcanzada a nivel mundial.

Diferencia entre factoring $y$ forfaiting El factoring es conveniente para la financiación de exportaciones de bienes de consumo con términos de crédito entre 90 y 180 días.

El forfaiting es usado para financiaciones de exportaciones de bienes de capital con términos de créditos de varios años.

El factoring no cubre los riesgos políticos y de transferencias, mientras que en el forfaiting estos riesgos son tomados por el comprador de las obligaciones.

Aplicaciones típicas y sus plazos

- Commodities (aceite, carbón, arroz, maíz, etc.). Financiamiento de 90 días a 18 meses.

- Servicios (ingeniería, diseño, mantenimiento, etc.). Financiamiento de 180 días a 3 años.

- Tecnología (software, computadoras, comunicaciones, etc.). Financiamiento de 180 días a 5 años.

- Bienes de Capital (herramientas, generadores, tractores, etc.). Financiamiento de 2 a 7 años.

- Plantas Industriales Energéticas (generadores de fuerza, producción de asfalto, etc.). Financiamiento de 3 a 10 años.

- Proyectos de Construcción (hospitales, aeropuertos, fábricas, etc.) con financiamiento de 3 a 10 años.

¿Qué es descontable?

Generalmente, para descontar una cuenta por cobrar sin recurso debe existir la documentación que sustente la deuda adquirida por el comprador al exportador: Esta deuda puede estar evidenciada por una diversidad de documentos tales como:
- Pagarés

- Letras de Cambio

- Cartas de Crédito/Cartas de Crédito en Stand by

- Garantías de Pago

En muchos casos, la deuda deberá contar con una garantía incondicional, irrevocable y de libre transferencia o con el aval de un banco conocido en el país del comprador. Sin embargo, en algunos casos, instituciones como London Forfaiting puede considerar a empresas corporativas de primer nivel o deuda de gobierno sin el respaldo adicional de un banco.

El forfaiting como ventaja competitiva En numerosos mercados los compradores prestan mayor importancia al flujo de caja que al precio de pago. Así, en muchos países, particularmente en mercados emergentes, donde se otorgan amplios plazos en las condiciones de pago aumentan considerablemente las alternativas de obtener un contrato.

El forfaiting permite al exportador cumplir con estas necesidades sin acceder a ningún riesgo adicional. Con un adecuado soporte, el exportador puede ofrecer financiarniento en base a pagos diferidos como parte de su propuesta, anticipándose así a las necesidades del comprador. Más aun, dirigiendo la negociación en las condiciones de crédito ofrecidas, el exportador puede esencialmente afrontar menos presión en reducir sus precios, lo cual a su vez conlleva mejorar los márgenes de venta y obtener un alto rendimiento.

El forfaiting ofrece a los exportadores flexibilidad mediante una sencilla estructura y así mejora su habilidad de ganar negocios en mercados internacionales competitivos. El forfaiting puede aplicarse como un paquete de soporte financiero individual o puede implementarse a créditos respaldados oficialmente por Agencias de Crédito para la Exportación (ECAs) tales como el Banco Ex-Imbank en los Estados Unidos.

Aprovechado en su propio beneficio, la flexibilidad del forfaiting habilita a los exportadores a ofrecer a sus clientes un financiamiento de hasta el $100 \%$ del valor contractual.

Otras ventajas

El forfaiting es un instrumento de venta altamente efectiva, la misma que simultáneamente mejora el flujo de caja y elimina el riesgo. Desde que los exportadores buscan expandir sus actividades en un creciente y volátil mercado global, recibirán inevitablemente más y más solicitudes de crédito. Los exportadores hoy en día necesitan una herramienta que les permita atender las necesidades de sus clien- 
tes, sin exponerse a riesgos y costos asociados a cuentas extranjeras por cobrar en sus balances.

Evidentemente, vender la deuda sin recurso mejorará el flujo de caja del exportador, proporcionándole una barrera contra la política, crédito y riesgos de transferencia generalmente asociados con préstamos en el extranjero.

Pero, la ventaja más significativa que ofrece el forfaiting es su utilidad como método de venta, específicamente en el caso de ventas en países cuyos compradores carecen de recursos para pagar contra entrega. Para los proveedores/exportadores en este sector del mercado, la habilidad para diferir pagos perjudicaría la aspiración de sus compradores/importadores. Integrando la solución al financiamiento dentro del contrato de venta, se puede ayudar al exportador a definir claramente una estrategia que mejore la probabilidad de ganar un contrato, incrementando el flujo de caja y eliminando el riesgo de no pago, a la vez que protege su margen de ganancia.

Beneficios del forfaiting para el

exportador

- El exportador recibe su pago en efectivo, asegurando y respaldando su flujo de caja y un balance más sólido.

- Hasta el 100,0\% del valor contractual puede ser financiado sin recurso. No existen requerimientos mínimos de pago inicial y no hay retención de riesgo por parte del exportador.

- El exportador se protege contra la demora en los pagos y no pagos resultantes de eventos de política, crédito, y transferencias.

- El exportador también se protege contra movimientos adversos en las tasas de interés y en los tipos de cambio internacionales.

- El exportador elimina la administración requerida a fin de cobrar los montos adeudados.

- El exportador podría ser capaz de obtener financiamientos de preembarque de sus bancos, contra un compromiso de los bancos financiadores (forfaiters) de descontar las cuentas por cobrar sin recurso.

- El exportador obtendrá una significativa ventaja comercial sobre los competidores que no utilizan el forfaiting y quienes, por lo tanto, no estarían en posición de ofrecer financiamiento de crédito de proveedor a mediano o largo plazo.

- Virtualmente, no hay restricciones en cuanto al tipo de producto, commodity o servicio a ser financiado y no hay limitaciones en cuanto a contextos extranjeros.

- El exportador puede hacer uso del forfaiting junto con numerosos programas gubernamentales de financiamiento a la exportación, y será capaz de acceder a subsidios locales donde los haya.
- El exportador mantiene contacto directo con el importador, y monitorea todas las discusiones financieras y comerciales que conllevan hasta la firma del contrato.

- Los bancos financiadores (forfaiters) pueden fijar tasas de interés hasta 18 meses previos a la fecha de embarque, protegiendo así al exportador de aumentos de tasas de interés, durante el período de manufacturación y entrega.

- Las condiciones de reembolso se estructuran de acuerdo a las necesidades de flujo de caja de los compradores, incluyendo períodos de gracia.

- La mayoría de las monedas son aceptables.

Beneficios del forfaiting para el importador

- El importador puede cubrir sus pagos con los ingresos proyectados, permitiéndose períodos de gracia.

- El importador puede obtener financiamiento del $100 \%$, y evitarse el pago por adelantado.

- El importador puede pagar el interés con una tasa básica fija mientras dure el crédito, lo cual transformar la transacción presupuestalmente en simple y segura.

- El importador puede acceder a condiciones de financiamiento de mediano y largo plazo, que puedan ser inalcanzables por su costo y no disponibles localmente.

- El importador es capaz de tomar ventaja de los esquemas de subsidios para exportaciones, los cuales están siempre disponibles por parte del gobierno del exportador.

Las empresas

Existen muchas empresas que son reconocidas mundialmente como empresas que operan en el mercado del forfaiting, como London Forfaiting Company PLC, Bank Boston, NedBank, Standard Bank, WestLB, entre otras. A la fecha las empresas han financiado operaciones de comercio exterior por billones de dólares dentro de más de sesenta países.

London Forfaiting Company PLC se formó en el año 1984 con el propósito de especializarse en el arreglo y provisión de forfaiting y otros productos financieros referidos al comercio exterior. La extensa experiencia de sus profesionales en forfaiting, complementada a su red global de oficinas asegura a sus clientes el alto nivel de servicio brindado. El capital de London Forfaiting Company PLC y la solidez de su balance revela la capacidad de sus recursos financieros a fin de mantener su compromiso de ser la primera. Actualmente ésta empresa ha crecido hasta convertirse en el líder mundial en el mercado del forfaiting, con acciones inscritas en la Bolsa de Valores de Londres 
La empresa emplea profesionales de diversas nacionalidades, con grados de conocimientos desde banca comercial e inversiones, hasta manufactura industrial y ventas, en un conjunto global de oficinas, cuenta con un vasto grupo de investigación autónomo dentro de las oficinas principales en Londres, con el fin de asegurarse de que las necesidades del cliente se atiendan debidamente y con rapidez. De hecho, en muchos casos la empresa atiende y cierra una oferta, a horas de haber presentado la solicitud.

\section{CASOS REALES}

Esta técnica de financiamiento se puede entender mejor mediante algunos ejemplos, que nos permitirán ilustrar cómo funciona una operación de Forfaiting y por ende cómo el forfaiting contribuye directamente al desarrollo de las exportaciones en el Mundo.

caso 1

Una pequeña empresa del Perú del sector textil, que exporta polos a EE.UU., tenía un balance débil y el Banco no le podía incrementar sus líneas de crédito, por lo que no sabía qué hacer para seguir exportando y atendiendo las demandas de sus clientes.

En suma, no tenía caja para atender más pedidos a tiempo y para abarcar un mayor mercado. Entonces, mediante el forfaiting, podía vender al banco sus cartas de crédito para recibir liquidez inmediata por adelantado. De esa forma la empresa podría seguir atendiendo más pedidos sin problemas y también ofrecer a sus clientes estadounidenses crédito de proveedor a mayores plazos, pudiendo competir con otros grandes textileros internacionales.

caso 2

Una mediana empresa del Brasil exportaba mensualmente prendas de vestir por un valor FOB de USD 160000 a un importador argentino; debido a la devaluación del Real en Brasil, el precio de sus prendas fue igualado con el precio de las procedentes del Brasil, aunque es cierto que las prendas del exportador eran preferidas por el importador argentino, éste decidió importar directamente las prendas ya que adicionalmente las empresas brasileñas, le ofrecían un plazo de pago de hasta 12 meses con tasas de interés muy interesantes.

Esta situación provocó la pérdida de las ventas con ese importador, con el inminente riesgo de perder el mercado. El exportador necesitaba encontrar una solución a este problema.

En busca de alternativas el exportador acudió a su banco. Después de haber planteado la situación, le indicaron que tendría que presentar una serie de documentos a fin de poder acceder a una línea de financiamiento y que si podía conseguir que su cliente aceptara letras o pagarés avalados por el banco del importador, el banco podría descontarlas a las tasas de interés vigentes en el mercado nacional.

Después de analizar las alternativas planteadas por su banco, concluyó que iba ser muy difícil transferir al importador los costos de financiar la exportación por los siguientes motivos:

- Tasa de interés muy altas que difícilmente serían aceptadas por el importador.

- El proceso de descontar los documentos de cobranza es largo y depende de la disponibilidad del banco, lo cual le generaba incertidumbre.

- Debería contratar un seguro de crédito de exportación, lo cual incrementaba los costos.

- Los plazos de financiamiento con los que venden los brasileños obligan a considerar el riesgo país, riesgo cambiario y riesgo político.

En definitiva, las alternativas de financiamiento de exportaciones que su banco la podía proporcionar eran caras y complicadas. El exportador desalentado se resignó a perder ese mercado.

Un amigo exportador de equipos de bombeo de España, que había llegado al país, le explicó que la moda en Europa era exportar empleando el Forfaiting. De esta manera, el exportador contactó con el broker de Forfaiting del exportador español y encontró la solución a su problema de financiamiento de la manera siguiente:

- Presentó al broker todos los detalles de la operación.

- El broker contactó con los bancos financiadores (forfaiters) y preparó una cotización detallada de la operación, para que el exportador pueda proponérsela al importador. Esta cotización especificaba 4 pagos semestrales ( 2 años) de acuerdo al Cuadro 1.

- Una vez que la operación fue aceptada por el importador, y su banco aceptó avalar los documentos del crédito o "promissory notes"(pagarés, letras de cambio o cartas de crédito) la operación del forfaiting quedaba pactada.

- El exportador mediante un contrato de venta o "commitment" con el banco forfaiter, cedió sus de-

Cuadro 1. Descuento usando tasa de interés semestral de 7.2\%

\begin{tabular}{|ccc|c|c|} 
Pagaré & Valor & Vencimiento & Descuento & Monto Neto \\
1 & 48776 & Semestre 1 & 3276 & 45500 \\
2 & 48266 & Semestre 2 & 6266 & 42000 \\
3 & 46567 & Semestre 3 & 8767 & 37800 \\
4 & 45826 & Semestre 4 & 11126 & 34700 \\
\hline Total & $\mathbf{1 8 9 4 3 5}$ & $\mathbf{2 9 4 3 5}$ & $\mathbf{1 6 0 0 0 0}$ \\
Fuente: Elaboración propia (Ejemplo 48,776/1.072= 45,500)
\end{tabular}


rechos de cobranza de dichos documentos y éste luego de la rápida confirmación de la operación del banco importador(banco garante o aval) procedió a cancelar los documentos emitidos menos los descuentos, de tal manera que el exportador recibe USD 160000.00 netos.

- Posteriormente el banco forfaiter cobro al banco garante los documentos conforme estos lleguen a sus vencimientos.

- Para que finalmente el banco garante haga la cobranza de los documentos al importador.

Como conclusión el exportador al emplear la técnica del forfaiting obtuvo los beneficios siguientes:

- Logró financiar sus operaciones de exportación a la Argentina con tasa de interés internacionales y a un plazo de 2 años.

- Con el forfaiting logró recibir al contado la cancelación del valor de su exportación en un plazo de 48 horas después de concretada la operación.

- No tuvo la necesidad de obtener un seguro de crédito de exportación.

- Usando el forfaiting logró eliminar el riesgopaís, riesgo cambiario y riesgo político; ya que cedió sus derechos de cobranza a un banco forfaiter, el cual asumía estos riesgos al momento de comprar.

Caso 3

Un exportador americano concluye un contrato con un importador taiwanes por un monto de US\$1 millón para la provisión de maquinaria textil. Según los términos del contrato, el importador efectua un pago inicial de US\$100 000, mientras que la diferencia de US\$900 000 dólares es pagada a plazo con crédito de los exportadores en 6 partes iguales. Además, 6 por ciento anual de interés sobre el insoluto o crédito pendiente de pago son asumidos por el importador.

Para resolver esta obligación, el importador emite una serie de 6 pagarés para el exportador con vencimiento consecutivo semestral desde 6 hasta 36 meses a partir de la fecha de embarque de las mercancías. A la fecha de embarque, 16 de mayo de 2002, los pagarés librados por el exportador se intercambian por el documento de embarque. Así el primer pagaré venció el 16 de noviembre 2002, el segundo el 16 de mayo de 2003, etc.

Con respecto al ingreso de cada uno de los 6 pagarés, el forfaiter pagó el valor descontado neto sobre la cantidad total al exportador usando un descuento de 6 por ciento anual, considerando que el tipo de interés cargado al importador iguala el tipo de descuento de los forfaiters. En este caso, no hay pagos por honorario de comisión y los cálculos del descuento incluyen una tolerancia de 5 días (o sea 5 días de gracia).
CONCLUSIONES

El forfaiting es una herramienta alternativa de financiamiento de exportación muy interesante cuando el exportador esta otorgando "crédito de proveedor" a sus clientes en el exterior, y le es complicado gestionar una línea de crédito tradicional de financiamiento de exportación.

El forfaiting aún no está bien difundido en el sistema financiero ni entre los exportadores peruanos. Esto se debe precisamente a la falta de conocimiento adecuado de este producto y de sus ventajas, por lo que el mercado del forfaiting es aún reducido en el país.

El costo de financiarse vía forfaiting es competitivo. La tasa de interés de descuento la negocian los sectoristas de los bancos financiadores (forfaiters) con sus clientes exportadores. Esta tasa se definirá en base al tipo de riesgo que representa el documento que está comprando el banco.

El forfaiting es una técnica en la cual la evaluación del riesgo país, por parte del banco forfaiter, es muy importante para la determinación de los plazos de crédito máximos por país y los márgenes adicionales al LIBOR (spread por riesgo país) que se emplearán para el descuento de los documentos. Por ejemplo, actualmente bajo condiciones normales tenemos que el mercado londinense de forfaiting, asigna las calificaciones siguientes: a la Argentina un plazo máximo de 3 años, a Brasil 4 años, a Bolivia 2 años, a Colombia 3 años, Venezuela 2 años, EUA 7 años, Alemania 7 años, entre otros.

B I B L I O G R A F́ A

1. Forfaiting Country List Trade \& Forfaiting Review (TFR). En: http://www.tfreview.com/ (6 junio 2005).

2. London Forfaiting Company PLC. En: http.// www.londonforfaiting.com/ (23 mayo 2005).

3. Negocios Internacionales.

En: http://www.comexperu.org.pe (28 junio 2005).

4. Página web de la International Forfainting Association (IFA). En: http://www.forfaiters.org/ (14 junio 2005).

5. Perú Exporta. En: http://www.adexperu.org.pe (28 junio 2005).

6. Trade, commodities, technology- posted $14 \mathrm{Jul}$ 2003 in Volume 6 Issue 9, Is forfaiting dead?. 